\title{
Modos de morar de pessoas com transtorno mental grave no Brasil: uma avaliação interdisciplinar
}

\author{
Accommodation of individuals with severe mental disorders \\ in Brazil: an interdisciplinary assessment
}

Juarez Pereira Furtado ${ }^{1}$

Augustin de Tugny ${ }^{2}$

Ana Paula Baltazar ${ }^{3}$

Silke Kapp ${ }^{3}$

Cláudia Maria Generoso ${ }^{4}$

Florianita Coelho Braga Campos ${ }^{5}$

Andréa Maris Campos Guerra ${ }^{4}$

Eunice Nakamura ${ }^{1}$

${ }^{1}$ Departamento de Políticas Públicas e Saúde Coletiva,

Unifesp. R. Silva Jardim 136,

Vila Mathias. 11.015-020

Santos SP Brasil.

juarezpfurtado@hotmail.com

${ }^{2}$ Escola de Belas Artes,

UFMG.

${ }^{3}$ Escola de Arquitetura,

UFMG.

${ }^{4}$ Departamento de

Psicologia, UFMG

${ }^{5}$ Departamento Saúde,

Clínica e Instituições,

Unifesp.

\begin{abstract}
Qualitative evaluative research is presented on the accommodation of people with severe mental disorders receiving mental health support from the city government in three large cities in Brazil. Participant observation of ten residents and their caregivers was conducted in Residential Therapeutic Services (SRT) and the routine of eight frequenters of Psychosocial Support Centers (CAPS) who established their accommodation on their own initiative was monitored. Both the residents of SRT and CAPS were interviewed in depth. The field material was analyzed by means of the interpretation method, from the perspective of architects, anthropologists, psychoanalysts and sanitary engineers. The findings indicate a lack of systematic processes of psychosocial rehabilitation of the residents of SRTs, caregivers unprepared to deal with the complexity of the residents' demands, in addition to low involvement of CAPS with SRTs. Moreover, users connected to the CAPS, who do not live in SRTs, showed a range of creative ways to establish their accommodation and greater interaction with the community, although some have the support of hostels and asylums to address their housing needs. At the end of the text, some directions to overcome the problems encountered are highlighted.

Key words Mental health, Accommodation, Public health, Anthropology, Psychoanalysis, Interdisciplinary research
\end{abstract}

Resumo Apresentamos pesquisa avaliativa qualitativa sobre modos de morar de pessoas com transtorno mental grave, vinculadas às redes municipais de saúde mental de três cidades de grande porte. Realizamos observação participante de dez moradores e respectivos cuidadores de Serviços Residenciais Terapêuticos (SRT) e acompanhamos o cotidiano de oito usuários de Centros de Atenção Psicossocial (CAPS) que constituíram suas moradias por iniciativas próprias. Os moradores e usuários também foram entrevistados em profundidade. O material de campo foi analisado, segundo o método interpretativo, da perspectiva de arquitetos, antropólogos, psicanalistas e sanitaristas. Os resultados apontam carência de processos sistemáticos de reabilitação psicossocial dos moradores de SRT e despreparo dos cuidadores para lidarem com a complexidade de demandas para seu acompanhamento, além de baixo envolvimento dos CAPS com os SRT. Por outro lado, usuários ligados aos CAPS, que não moram em $S R T$, apresentaram criativa diversidade nos modos de constituir suas moradias e maior interação com a comunidade, embora alguns contem com o apoio de albergues e asilos para resolver suas necessidades. Algumas direções para a superação dos problemas encontrados são apontadas ao final do texto.

Palavras-chave Saúde mental, Habitação, Saúde coletiva, Antropologia, Psicanálise, Pesquisa Interdisciplinar 


\section{O problema}

A demanda por moradias de pessoas com transtorno mental grave (TMG) é uma implicação fundamental da mudança do modelo de assistência em saúde mental no Brasil, uma vez que prioriza o direcionamento do cuidado para a comunidade, superando a centralidade do hospital psiquiátrico. Tanto aqueles que deixaram tais hospitais quanto aqueles que, por meio do acompanhamento dos Centros de Atenção Psicossocial (CAPS), prescindiram de internações prolongadas, apresentam necessidades peculiares de habitação nesse novo contexto ${ }^{1,2}$.

A portaria 106/2000 do Ministério da Saúde 3 oficializou os Serviços Residenciais Terapêuticos (SRT) no SUS para suprir a parte dessa demanda constituída por pacientes 'moradores' de hospitais psiquiátricos públicos e privados do Brasil. Segundo a estrutura básica, o modo de operar e o financiamento estabelecidos na referida portaria, SRT são casas inseridas preferencialmente no espaço urbano, destinadas a receber até oito egressos, que deverão ter suporte clínico e reabilitação psicossocial da rede municipal de saúde mental. Por outro lado, ainda não há políticas de moradia especificamente voltadas para a outra parte da demanda, constituída pela clientela dos quase dois mil CAPS existentes ${ }^{4}$. São milhares de pacientes, muitos considerados graves, que justamente em razão do acompanhamento na comunidade, não têm histórico de longas internações em hospitais psiquiátricos e não têm acesso aos SRT.

As necessidades de moradia não devem ser subestimadas. Como determinante social da saúde em geral ${ }^{5}$ e da saúde mental em particular, a moradia é decisiva na inserção, integração e manutenção de pessoas com TMG no meio social ${ }^{6}$. Nela convergem importantes aspectos do indivíduo, do mais íntimo e pessoal até o social e relacional $^{7}$. Para pessoas com TMG, a habitação pode oferecer um espaço de complacência com eventuais sintomas e um ponto de partida para interações que ultrapassam o morar, mas que dele dependem ${ }^{8}$. Como sintetiza Saraceno' ${ }^{9}$ a moradia forma, junto com a rede social e o trabalho, a tríade fundamental no processo de reabilitação e inserção social, sendo que a noção de moradia inclui não só a estrutura física, mas também as diferentes maneiras de apropriação do espaço ou os modos de habitá-lo.

Diversos estudos internacionais apontam resultados positivos no âmbito da desinstitucionalização psiquiátrica e ganhos significativos para os usuários de moradias assistidas ${ }^{10-12}$. Tsemberis $^{13}$ defende modelos de habitação plenamente integrados na comunidade e, mais que flexíveis, transigentes com as muitas questões que atravessam a psicose e o uso abusivo de drogas. Trieman et al. ${ }^{14}$ realizaram estudos prospectivos em que 670 pacientes oriundos de dois hospitais psiquiátricos de Londres foram acompanhados por cinco anos, analisando-se fatores como qualidade de moradia, frequência de reinternações e situações de desabrigo (homelessness). A conclusão é que, se bem planejados e estruturados, os cuidados às pessoas com TMG em casas inseridas na comunidade são benéficos e não trazem riscos para os demais segmentos da sociedade.

Também no Brasil o advento dos SRT e o avanço do tratamento comunitário têm impulsionado estudos sobre as condições de moradia da clientela, permitindo traçar paralelos entre a vida no hospital e na nova moradia ${ }^{15-17}$ e compreender eventuais repercussões na subjetividade dos usuários ${ }^{18,19}$. Já no que diz respeito a pessoas com TMG que habitam moradias constituídas por elas mesmas a partir de recursos próprios, a literatura especializada brasileira tem se restringido à interface entre moradores de rua $\mathrm{e}$ doença mental ${ }^{20}$.

Soma-se a essa lacuna um segundo aspecto ainda relativamente pouco contemplado nas pesquisas brasileiras sobre o tema: o seu caráter interdisciplinar. A complexidade intrínseca ao morar e suas múltiplas relações com a (re)inserção social nos parecem tornar imprescindível a interdisciplinaridade, isto é, a tentativa de efetiva articulação entre diferentes perspectivas e áreas do conhecimento.

Por meio de um financiamento do Conselho Nacional de Desenvolvimento Científico e Tecnológico $(\mathrm{CNPq})$, realizamos um estudo que procura contribuir para fechar essas duas lacunas ${ }^{21}$. Trata-se de um projeto interdisciplinar de pesquisa avaliativa qualitativa e participativa acerca da situação de moradia de dois grupos de pessoas com TMG: (1) aquelas que tentam constituir ou efetivamente constituem sua própria habitação, seja por vontade própria ou por não contarem mais com a residência de familiares ou o apoio institucional nesse sentido; (2) aquelas que, após longas internações psiquiátricas, passam a morar com outros egressos nos SRT. Salientamos nossa opção em analisar aspectos intrínsecos a cada situação, evitando comparações entre os tratamentos asilar e comunitário - como dito acima, elas já estão disponíveis no contexto nacional e internacional e são claramente favoráveis a este 
último. Além disso, em se tratando de pesquisa avaliativa $^{22}$, apontamos questões e possíveis caminhos ao final das discussões. Este estudo foi aprovado pelo Comitê de Ética da Unifesp.

\section{O método}

O estudo abrangeu três cidades brasileiras, reunindo pesquisadores de três universidades e quatro áreas do conhecimento: Arquitetura, Antropologia, Psicanálise e Saúde Coletiva (Figura 1). Inicialmente, definiu-se um roteiro comum de observação e coleta para os trabalhos de campo, a partir de visitas-teste realizadas por pesquisa- dores de cada uma das áreas. Os trabalhos de campo transcorreram de setembro de 2009 a abril de 2010. Dentre os três municípios escolhidos, dois são capitais de Estado (Sudeste e CentroOeste) e o terceiro, igualmente de grande porte, integra uma região metropolitana no Sudeste. Os três têm em comum a existência de uma rede municipal de saúde mental implementada há mais de cinco anos, constituída por CAPS, SRT, Centros de Convivência e relações com a Atenção Básica e serviços de emergência.

Utilizando um referencial qualitativo de pesquisa, os trabalhos de campo consistiram em observações participantes e entrevistas individuais em profundidade com pessoas dos dois grupos
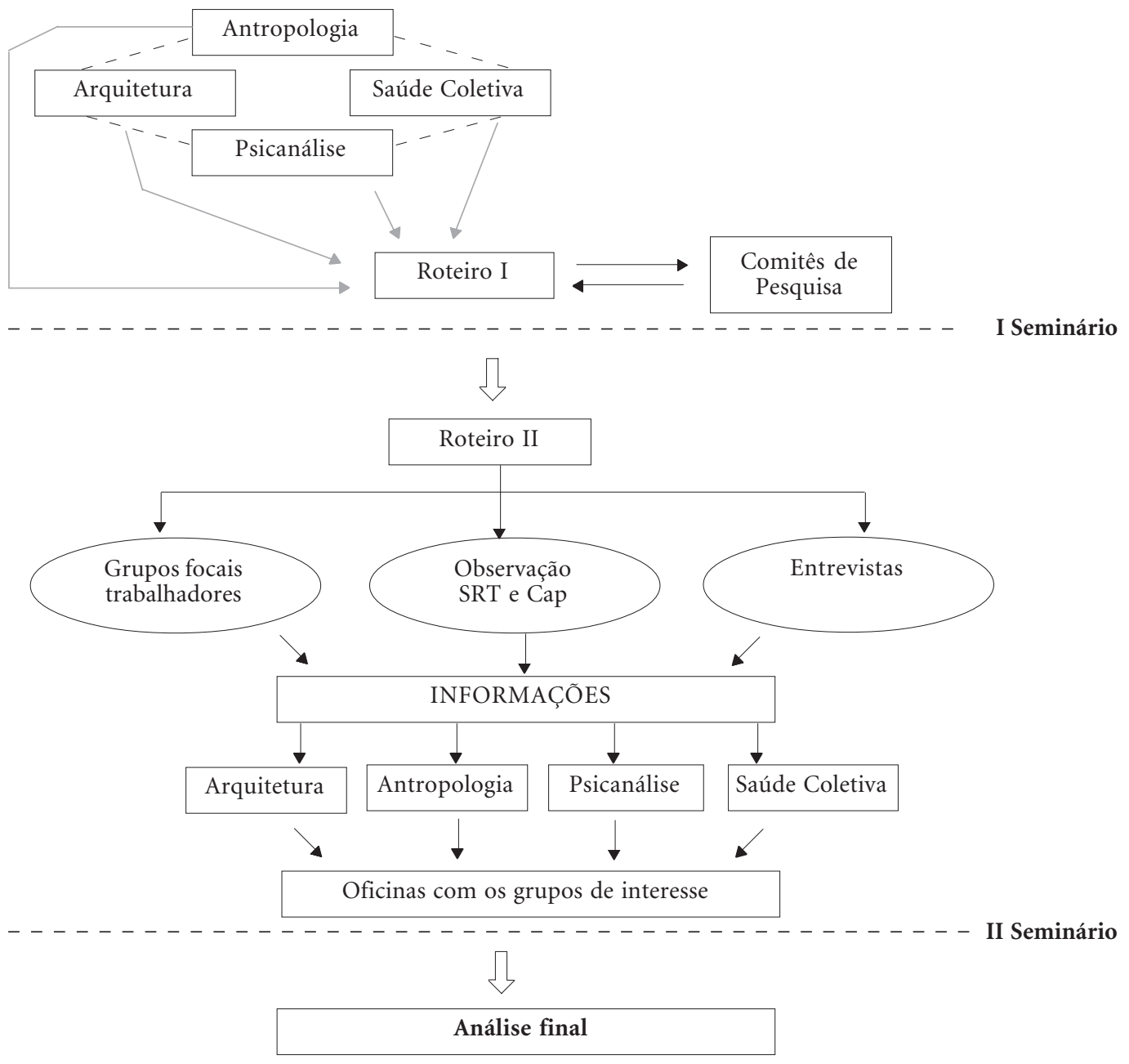

Figura 1. Delineamento da metodologia. 
acima delineados. O primeiro grupo (1) foi composto de oito usuários de CAPS que moram por conta própria. As equipes dos respectivos CAPS definiram esses usuários a partir de um critério que estabelecemos previamente: metade seriam pessoas que, na perspectiva da equipe, tivessem resolvido satisfatoriamente suas necessidades de moradia; outra metade seriam pessoas cuja situação de moradia a equipe considerasse problemática (o que, via de regra, coincidiu com a condição de sem-teto ou de pernoite regular em abrigo público). O segundo grupo (2) foi composto por um total de 10 moradores de SRT. A escolha desses SRT, dois em cada cidade, se fez juntamente com as Coordenadorias de Saúde Mental locais, a fim de garantir a participação de diferentes atores sociais (gestores, profissionais de saúde, cuidadores e moradores) na pesquisa avaliativa. Já a escolha dos moradores que seriam individualmente observados e entrevistados em cada SRT se deu pelo grau aparente de adaptação à moradia, priorizando moradores particularmente bem ou particularmente mal adaptados.

Os chamados cuidadores - profissionais sem formação específica, normalmente com o primeiro grau completo e contratados de forma terceirizada por ONG - foram indiretamente observados, na medida em que estão em constante interação com os moradores dos SRT. Tanto os usuários de CAPS quanto os moradores de SRT foram acompanhados em suas rotinas diárias dentro e fora de casa, em diferentes períodos da semana, buscando-se observar a configuração da moradia (aspectos físicos), a experiência dos moradores (o significado de habitar, a organização das pessoas no espaço de moradia) e sua inserção social (rede de relações dos moradores na comunidade). As entrevistas com os dois grupos seguiram um mesmo roteiro semiestruturado básico, contemplando: elementos físicos, funcionamento e modos de apropriação das respectivas moradias; relação com outros moradores, trabalhadores da saúde e vizinhança; participação nas decisões sobre o espaço de moradia; avaliação da (in)adequação desse espaço às necessidades do entrevistado; e o processo de acompanhamento, tratamento e reabilitação. Nas entrevistas com os usuários de CAPS (grupo 1), acrescentaram-se ao roteiro básico perguntas sobre a forma de acesso à moradia e as razões para não morar num SRT.

Concluído o trabalho de campo, o material foi transcrito e analisado com densidade, segundo o método interpretativo e a partir da perspectiva de cada uma das quatro áreas e das respecti- vas categorias teóricas e empíricas (Quadro 1). Além do intenso contato via rede de computadores, as discussões se realizaram em dois seminários presenciais com todos os pesquisadores $\mathrm{e}$ efetiva participação também de gestores e trabalhadores dos campos envolvidos.

\section{Resultados e Discussões}

\section{Perspectiva da Saúde Coletiva}

A partir da interação com o campo e do material gerado, definiram-se três eixos de análise relacionados ao modelo tecnoassistencial ${ }^{23}$ : equipe de referência, reabilitação psicossocial e promoção de autonomia. No primeiro eixo, examinou-se o estabelecimento de relações entre profissionais de diferentes categorias em torno de uma clientela específica, visando vínculo e resolutividade ${ }^{24}$. Seu grau de implementação foi analisado pelos planos comuns de trabalho, pela interação de diferentes profissionais entre si e com os pacientes, e pelo eventual apoio institucional às questões intersubjetivas dos trabalhadores. No segundo eixo, a reabilitação psicossocial compreendida como contínuo aumento de inserção e circulação sociocultural e político-econômica dos usuários $^{9,25}$, a análise partiu dos projetos terapêuticos individuais e do grau de particularização dos cuidados dispensados aos usuários. Finalmente, a promoção de autonomia ${ }^{26}$, compreendida como a possibilidade de os usuários interferirem em seu processo de reabilitação no espaço físico e social de sua moradia, bem como o seu acesso a espaços e momentos de privacidade, foi analisada com base nos acompanhamentos dos cotidianos realizados. Há evidentes avanços nos SRT dos três campos em relação aos problemas gerados pela inserção prolongada em hospitais psiquiátricos. No entanto, algumas questões foram observadas com base nos eixos aqui apresentados.

As equipes de referência e a interação cotidiana entre diferentes categorias profissionais é algo a ser ainda implementado nos três cenários da pesquisa. Os cuidadores são os principais e frequentemente únicos profissionais presentes ao lado dos moradores de SRT. Suas atribuições vão dos trabalhos doméstico de limpeza e alimentação até o estímulo à aquisição de autonomia pelos moradores e a administração de conflitos entre eles. Nesse leque excessivamente amplo, os cuidadores privilegiam tarefas visíveis e tangíveis que, por isso mesmo, estão submetidas ao crivo 
Quadro 1. Categorias de análise e referenciais das quatro áreas envolvidas.

\begin{tabular}{|l|l|l|}
\hline \multicolumn{1}{|c|}{ Áreas } & \multicolumn{1}{|c|}{ Categorias teóricas } & \multicolumn{1}{c|}{ Referenciais } \\
\hline Saúde Coletiva & $\begin{array}{l}\text { - intersetorialidade das ações } \\
\text { - organização do trabalho interprofissional } \\
\text { - gestão da clínica } \\
\text { - particularização do cuidado } \\
\text { - promoção de autonomia }\end{array}$ & $\begin{array}{l}\text { - Método Paidéia } \\
\text { - Avaliação de quarta geração }\end{array}$ \\
\hline Antropologia & $\begin{array}{l}\text { - significado } \\
\text { - inserção social e cultural } \\
\text { - experiências de habitação } \\
\text { - relações sociais } \\
\text { - pessoa }\end{array}$ & $\begin{array}{l}\text { - Método interpretativo } \\
\text { - Significado }\end{array}$ \\
\hline Arquitetura & $\begin{array}{l}\text { - Pessoa } \\
\text { - relações moradia-habitação } \\
\text { - formulação do habitar } \\
\text { - instrumentos para avaliação do habitus } \\
\text { - produção social do espaço }\end{array}$ & $\begin{array}{l}\text { - Subjetividade do habitar } \\
\text { - Interfaces }\end{array}$ \\
\hline Psicanálise & $\begin{array}{l}\text { - Posição na linguagem (simbólico) - sujeito do espaço } \\
\text { - Laço do sujeito com o Outro social } \\
\text { - Transferência e rede } \\
\text { - Savoir-y-faire com o sintoma }\end{array}$ & $\begin{array}{l}\text { - Clínica da psicose } \\
\text { - Psicanálise Aplicada } \\
\text { - Psicanálise e Instituição }\end{array}$ \\
\hline
\end{tabular}

Fonte: Furtado et al. ${ }^{22}$

direto de colegas e superiores. Ações voltadas para a reabilitação psicossocial, de longo prazo e de efeitos sutis, que requerem mais trabalhadores e saberes especializados, são preteridas em favor da organização do cotidiano das casas. Tal contexto, de restrita quantidade e diversidade de profissionais, reduz as possibilidades de vinculações e trocas para os moradores.

Como decorrência, são escassos os projetos terapêuticos formulados de maneira individualizada para os moradores de SRT. Há evidente acompanhamento da saúde bucal e clínica, porém a pouca articulação de profissionais de distintas áreas em torno de um plano terapêutico para cada um dos moradores dificulta a particularização da atenção e fomenta a padronização das tarefas cotidianas, tornando os processos de reabilitação psicossocial bastante restritos.

A situação é diferente para os usuários dos CAPS que moram por conta própria, pois, via de regra, contam com pelo menos um profissional universitário de referência, que reconhecem e valorizam e com o qual têm encontros periódicos. Os espaços públicos e os próprios CAPS, nesses casos, expõem usuários e trabalhadores a mais demandas e possibilidades de negociação provenientes de territórios externos. O que pare- ce constituir um paradoxo: conforme discutido da perspectiva da Arquitetura, a cidade moderna tende a ser um espaço de difícil apreensão para cidadãos em geral e para aqueles com fragilidades psíquicas em particular; no entanto, os desafios da vida urbana parecem constituir estímulos importantes no processo de reabilitação de portadores de TMG.

Poderíamos sintetizar que os pacientes que moram por conta própria (com ou sem a ajuda de terceiros) são mais próximos aos CAPS e têm equipes de referência e processo de reabilitação psicossocial elaborado pelos profissionais universitários. Já os moradores de SRT, acompanhados pelos cuidadores, acabam por não contar com a atenção de uma equipe multidisciplinar, nem com projetos de reabilitação psicossocial particularizados ${ }^{3}$.

Contudo, no que tange à promoção da autonomia - à possibilidade de interferir em normas e regras e ao direito à privacidade no cotidiano cabe nuançar alguns aspectos. Os portadores de TMG residentes em asilos e albergues demostraram grande necessidade de submissão às regras das respectivas instituições para garantir sua permanência ali. Já os moradores de SRT são submetidos a regras múltiplas e muitas vezes anta- 
gônicas, pois é comum que cada cuidador faça valer parâmetros e rotinas próprios durante o seu plantão. Pudemos observar que parte desses moradores tem capacidade de subverter tais regras, criar estratagemas para ludibriar o controle e tomar iniciativas, como ilustra o incremento do cardápio padronizado mediante a compra de alimentos com recursos próprios (dos benefícios). Porém, os moradores de SRT, assim como os de albergues e asilos, dificilmente contam com espaços de privacidade ou distanciamento do olhar e da escuta alheios. Em ambas as situações são constantes a presença e o controle dos trabalhadores e dos colegas de moradia. Apenas nas moradias em pensão ou imóvel alugado encontramos esses espaços de privacidade.

\section{Perspectiva da Antropologia}

A abordagem antropológica privilegiou os conceitos de "significado" e "pessoa", para compreender como ocorre a inserção social dos sujeitos particulares desta pesquisa, a partir dos significados que cada um atribui à sua moradia $\mathrm{e}$ à sua própria vida. A ideia do significado, na perspectiva antropológica, pressupõe a interação entre pensamento e experiência ${ }^{27}$; o que implica que, ao se analisar o significado de moradia para pessoas em situação de sofrimento mental seja necessário conhecer o modo como vivem e se organizam nas moradias. A categoria "pessoa", tomada como unidade socialmente investida de significação ${ }^{28}$, permite analisar tensões entre os diferentes modos pelos quais os homens se realizam no mundo.

De maneira geral, os SRT acompanhados se caracterizam por uma padronização na disposição de móveis e objetos imposta aos moradores, bem como pela normatização de seu uso: na maioria deles, proíbe-se a utilização do fogão e de fósforos e facas, alegando-se razões de segurança. Por outro lado, os pacientes que não moram nos SRT vivem em situações heterogêneas (casa, cortiço, albergue, abrigo, pensão ou mesmo nas ruas da cidade) e parecem dispor de mais possibilidades de criação e recriação de móveis e objetos. A mala que se torna mesa, o aparador feito de tábuas e forrado com tecidos coloridos, a pilha de tijolos usada como varal - tudo isso evidencia uma capacidade de improviso que tende a ser interditada nos SRT.

Nas diferentes possibilidades de criação ou recriação, mais ou menos limitadas, os moradores organizam modos particulares de habitar em função do que é dado, escolhido ou transforma- do. Atribuem algum sentido e coerência às suas experiências de moradia, na medida em que interagem com outras pessoas, inserindo-se minimamente na vida social e cultural do grupo. O aspecto relacional de suas experiências implica compreender como se constituem como pessoas. Esse segundo conceito privilegiado na perspectiva antropológica, a noção de pessoa, permite analisar relações e tensões no modo como os moradores se reconhecem inseridos na vida social e são reconhecidos nesse sentido pelos outros. A despeito de sua condição de pessoas com TMG, alguns parecem reconhecer um lugar possível na vida para si: "um lugar ao sol, um cantinho para morar", segundo o depoimento de um dos moradores de SRT.

Nos SRT, as relações sociais dos moradores entre si e com os cuidadores apresentam conflitos inevitáveis, na medida em que se exige desses atores sociais constante ajuste a formas possíveis de sociabilidade e trocas, levando-os muitas vezes a optarem pelo isolamento. Em geral, os cuidadores solucionam os conflitos atuando como mediadores e evitando que os moradores fiquem irritados ou briguem. Ao mesmo tempo, há situações de conflito geradas pela desconfiança de alguns moradores em relação aos cuidadores ou por brincadeiras, atitudes inconvenientes, provocações e impaciência destes últimos. Entre os pacientes dos serviços de saúde mental dos CAPS, por outro lado, as relações sociais são menos conflituosas.

Em ambas as situações, nos SRT ou nas experiências fora deles, é evidente a existência de regras e valores morais que orientam moradores, pacientes e cuidadores no modo como agem ou se comportam uns com os outros, definindo papéis e lugares sociais para possibilitar a convivência. Moradores dos SRT entre si e pacientes de CAPS demonstram que suas relações sociais se baseiam em respeito e reciprocidade, ao passo que as relações entre moradores e cuidadores são muito mais pautadas na obediência à ordem e à disciplina.

Esses diferentes grupos parecem mover-se no interior de uma lógica capaz de orientá-los no mundo ${ }^{29}$. A apreensão, na análise antropológica, de uma 'ordem' ou de uma 'lógica' possível nas experiências desses moradores, revela como os significados são compartilhados por pessoas que habitam de algum modo suas moradas, lançando mão principalmente dos elementos disponíveis em suas lembranças de vivências socioculturais anteriores à sua internação e que agora são parcialmente retomadas, como as peças de um 
quebra-cabeça complementado por sua vida cotidiana: "operando à semelhança do bricoleur (...) utilizam elementos disponíveis na realidade, obrigando-se a buscar soluções ou realizar arranjos recorrendo a esse conjunto de elementos" ${ }^{30}$.

A noção de significado é complementada pela de pessoa, evidenciando um contexto em que as relações sociais estabelecidas possibilitam o tráfego de símbolos, na medida em que se sustentam por meio de regras, valores e no respeito ao outro. Esses dois aspectos ressaltados na análise apontam dimensões que devem ser observadas em relação às pessoas com TMG, pois na medida em que passamos a compreender como se constituem social e culturalmente como pesso$\mathrm{as}^{31}$, podemos contribuir para processos que levem à sua (re)inserção social, mesmo que para isso tenhamos que considerar a maneira particular e frágil pela qual se constituem como outras possibilidades de pessoas. Tal particularização parece contrapor-se, assim, às formas de padronização, imposição e proibição às capacidades de criação de (re)criação dos espaços e das relações sociais.

\section{Perspectiva da Arquitetura}

Habitar significa mais do que a utilização físico-funcional de uma construção. A configuração espacial da moradia e da cidade possibilita ou interdita gestos e comportamentos, baliza e reflete formas de sociabilidade, participa na constituição de identidades e na integração de memórias coletivas e individuais. Assim, a análise das formas de habitação das pessoas com TMG a partir do campo da arquitetura procurou abranger essas múltiplas dimensões da interação de indivíduos e grupos com objetos e situações espaciais.

Nos SRT constatamos a tentativa de reprodução simbólica da 'casa de família', a começar pelo fato de eles se instalarem em imóveis originalmente destinados ao uso residencial unifamiliar. Porém, não há nenhuma relação familiar entre os moradores dos SRT, nem tampouco esse modelo da casa de família foi reivindicado por eles. Cria-se assim uma situação ambígua quanto à reconstrução da autonomia dos moradores. Por um lado, o caráter 'familiar' dos espaços sugere possibilidades amplas de criação de identidade, expressão e desenvolvimento pessoal. Por outro, a existência de um modelo predefinido e sua supervisão institucional impõem configurações físicas e papéis aos moradores e cuidadores. Alguns móveis e outros objetos, por exemplo, provêm do clássico cenário doméstico, mas são tratados como 'patrimônio público' e têm seus lugares definidos prioritariamente pelas necessidades dos cuidadores (supervisão, controle, facilidade de limpeza etc.). Eles não constituem objetos com os quais os moradores configuram ambientes pessoais e ampliam suas possibilidades de ação no cotidiano, como seria de se esperar num espaço 'caseiro'. Quando ocorrem alterações de uso em relação ao previsto nos projetos originais das casas, trata-se de pequenas inversões funcionais (como a sala que se torna quarto ou a entrada secundária que se torna principal), nunca de subversões estruturais.

Também a interação dos moradores dos SRT com a cidade se define pela falta de autonomia e pela tutela. Vão ao forró, ao cinema, ao centro de convivência e à padaria, ficam no portão, andam de táxi ou de ônibus, mas tudo isso são atividades "pro tempo passar" - como diz um morador. Elas não favorecem a apropriação da cidade pelos indivíduos, sua inserção social no sentido mais amplo ou mesmo uma simples "inserção funcional” pelo trabalho ${ }^{32}$. Assim, a tríade moradia, trabalho e rede social ${ }^{9}$ é banalizada: a moradia reproduz a casa de família, o trabalho é considerado apenas ocupação terapêutica desinserido da economia da cidade e a rede social praticamente inexiste.

No que diz respeito às pessoas com TMG que moram por conta própria, as situações são diversas e não generalizáveis. Identificamos várias situações que sugerem o delineamento de mapas mentais ou geografias imaginárias, com o reconhecimento de marcos e lugares onde há trocas socioespaciais e mesmo ações relativamente autônomas no espaço urbano. O que potencializa essas experiências são os acasos que a grande cidade providencia e que cada um pode aceitar ou rejeitar à sua maneira. Por outro lado, essas experiências também são debilitadas pela frieza que rege as relações urbanas e pelos medos, dificuldades, angústias e inseguranças, que geram.

A relação entre as pessoas com TMG que moram sozinhas e as instituições com as quais precisam lidar no cotidiano urbano também provocam vontades e resistências que nos parecem importantes indícios do processo de inserção social. Assim, por exemplo, lidar com dinheiro mediante uma meticulosa contabilidade ou uma recusa categórica das trocas comerciais - identificamos os dois extremos - são ambas atitudes que pressupõem um posicionamento do sujeito no jogo das instituições. Esse posicionamento não se estabelece de modo tão claro nos SRT, sendo 
velado pela relação hierárquica entre cuidadores e moradores e pela configuração tradicional da casa de família, que acabam assegurando ao sujeito um papel subordinado e fictício. Já os que moram de outras maneiras, lidam cotidianamente com tais instituições, não lhes sendo interditada a intermediação socioespacial.

Se o modelo de casa de família adotado pelos SRT dificulta a inserção social de seus moradores no espaço urbano, e se, por outro lado, há fragilidades evidentes na condição de moradia das pessoas que estão por conta própria, ficam as seguintes perguntas: É possível formular a inserção social dos pacientes de TMG sem ter por princípio a inserção funcional? Há algum modelo de moradia possível? Será possível procurar por um modelo na lógica vigente de produção e oferta de espaço de moradia no mercado imobiliário? A quantidade de pessoas com TMG não justificaria um investimento maior e mais adequado na sua inserção social e nos espaços que habitam?

\section{Perspectiva da Psicanálise}

Sob a ótica da psicanálise, a questão de habitação e inserção social considerou dois aspectos: (1) a singularidade dos modos de viver de cada sujeito; (2) e como a dimensão de casa se articula às possibilidades subjetivas referidas ao íntimo em sua relação com o Outro. Esses dois aspectos relacionam-se com noções teóricas presentes desde o início da pesquisa: posição do sujeito na linguagem, saber fazer com o sintoma e a relação com o Outro. A elas se acrescentaram a noção de íntimo e de desinserção, como frutos do processo de investigação.

Para a psicanálise, o sujeito diz respeito à experiência do inconsciente. $\operatorname{Lacan}^{33}$, na interpretação do texto freudiano, revela que é na linguagem que o sujeito do inconsciente se manifesta, sendo uma experiência fugaz, na qual se abre uma fenda por onde algo de não sabido surge, configurando-se nas vivências dos atos falhos, sonhos, sintomas que se expressam no corpo e no indivíduo que fala. Há um ponto de desconhecimento radical de si mesmo que condiciona a entrada do sujeito na linguagem, no simbólico, como resposta aos embaraços que o corpo e as pulsões lhe apresentam.

A hipótese do singular de cada morador em seus modos de habitação, surgida ao longo do acompanhamento dos casos, levou os pesquisadores a perceberem que a habitação segue o estilo do morador na medida em que comporta a natureza de seu sintoma como tentativa de (re)construção do mundo subjetivo. Nesse sentido, a posição na linguagem de cada sujeito interfere na (re)construção do seu modo de habitar a vida, tal como os paranoicos que evidenciam uma relação mais consistente com o Outro, os esquizofrênicos que buscam soluções mais referidas ao corpo, os melancólicos que se destacam pelas suas dificuldades para sustentar o Outro. São observações que devem ser consideradas, mas não entendidas de forma a engessar soluções conforme o tipo clínico, o que levaria a uma leitura reducionista.

Posta essa advertência, relembramos a hipótese deduzida de nossa investigação, que nos levou a observar o quanto a habitação subjetiva é composta por artifícios que cada um arranja para tentar cingir os pontos de ruptura com o mundo personificado pelo Outro e/ou pelo corpo. Pudemos fazer também uma articulação dessa hipótese com aquela retirada do ensinamento de Lacan $^{34}$ - "o homem encontra sua casa em um ponto situado no Outro" - na medida em que o caminho por aí traçado se constitui na tentativa de cada um em reparar o ponto de ruptura e, por conseguinte, de ausência em que o sujeito se encontra no Outro. Delimita, assim, por consequência, um lugar, uma casa na qual essa ausência pode se alojar. O singular da ruptura e da desinserção de cada um se manifesta, então, como orientação universal a ser seguida para pensar a forma de apropriação da moradia, tal como vimos nos diferentes casos pesquisados, particularizada a posição do sujeito no mundo e no laço social.

Pudemos observar diferentes tentativas criativas de habitação, dentre aqueles que moram de outras maneiras que não os SRT, indicando possíveis laços com o Outro, com o corpo, os objetos e com as ofertas do mundo. Nessa perspectiva, tomamos a noção de íntimo em sua articulação com a casa e a resposta sintomática do sujeito, destacando que cada morador tenta se arranjar como pode para criar uma esfera íntima, buscando seus recursos para se proteger do domínio e do olhar do Outro e conseguir habitar minimamente o mundo. Dessa maneira, constitui seu espaço íntimo, apoiado na possibilidade do esconderijo, do secreto, o espaço onde o sujeito pode se manter e se sentir fora do olhar do Outro. Um espaço de exclusão interna, que se chama a "sua casa"

Nesse caso, seria importante que os representantes do Outro para cada sujeito pudessem considerar essa dimensão do íntimo no manejo de relações e vínculos transferenciais com os mora- 
dores. Os moradores que vivem em espaços que não os SRT, parecem encontrar saídas mais inventivas para habitar o mundo, fazendo uma composição mais razoável com o Outro. Ainda que o Outro seja o corolário da posição do sujeito na linguagem e, enquanto tal, não generalizável, pudemos verificar que os SRT, enquanto representantes do Outro do cuidado, ainda são pouco expressivos na potencialização das formas criativas, singulares, de habitar, esboçadas por cada morador. De uma maneira geral, deparamo-nos nos SRT com a dificuldade de construção de um estilo próprio de lidar com a vida e consigo mesmo, sobressaindo a ideia de casa conforme uma visão mais padronizada e enrijecida pelos modelos sociais de habitação. Talvez essa posição possa ser um índice para pensar a maneira mais tutelada ou dependente de grande parte dos moradores habitarem suas moradias, permanecendo os SRT como lugares de oferta de cuidados básicos do cotidiano, ficando ainda muito tímidos em ocupar uma posição de operadores de transformação subjetiva e social a partir da singularidade de cada morador.

\section{Conclusões}

Na colaboração interdisciplinar, um conceito emergiu a partir do trabalho empírico e foi compartilhado pelas quatro áreas: autonomia. A noção de autonomia se cristalizou nas análises como possibilidade de as pessoas com TMG, em suas diferentes experiências de moradia, terem espaços e momentos de privacidade, interferirem nas normas e regras dos locais de moradia, poderem exercer sua criatividade na interação com espaços, objetos e outras pessoas, e reconstruírem suas relações com a cidade.

O resultado final desta investigação guarda as especificidades de cada área e, simultaneamente, apresenta compartilhamento conceitual, como apontado acima. Por outro lado, além das questões de ordem epistemológicas necessariamente envolvidas, devemos ressaltar nossa concepção de colaboração disciplinar do tipo interdisciplinar como um processo de debate e interação entre diferentes perspectivas que não visa a homogeinização, a onisciência ou mesmo a criação de uma superciência. A afirmação de Fourez ${ }^{36}$ reflete nosso aprendizado oriundo da experiência de intensa cooperação e elaboração coletiva, quando pudemos perceber como uma das marcas do trabalho interdisciplinar a [...] negociação entre diferentes pontos de vista para enfim decidir sobre a representação considerada como adequada tendo em vista a ação. [...] É preciso aceitar confrontos de diferentes pontos de vista e tomar uma decisão que, em última instância, não decorrerá de conhecimentos, mas de um risco assumido, de uma escolha finalmente ética e politica.

A partir de aproximações conceituais e dos distanciamentos inerentes ao fato de serem áreas distintas, constituímos convergências que permitiram a formulação de proposições para subsidiar tomadas de decisão em relação ao objeto avaliado, conforme se preconiza em pesquisas avaliativas $^{22}$.

Com relação aos SRTS, depreende-se a necessidade de diversificação de opções, uma vez que a estruturação do espaço de habitação requer plasticidade aos intentos de seus moradores e flexibilidade no suporte. Mas trata-se de uma diversificação não restrita à simples ampliação dos tipos predefinidos que irão impor ao sujeito e às suas necessidades específicas a construção de ideais externos. Nesse sentido, o singular e o específico se apresentam como baliza para iniciativas de constituição e efetiva apropriação de moradias por parte das pessoas com TMG.

Os cuidadores, responsáveis em maior parte por todo o acompanhamento dos moradores de SRT, recebem pouco ou nenhum apoio, sendo a educação permanente muito restrita e descolada de suas necessidades. A preocupação dos cuidadores em manter a ordem dificulta a escuta e o acolhimento de demandas que fujam à rotina. $\mathrm{Na}$ falta de outros referenciais, os cuidadores baseiam suas condutas em suas próprias vivências e valores morais. Dessa forma, os moradores dos SRT acompanhados carecem de processo de reabilitação psicossocial individualizado e permeável às nuanças de cada um, o que requer dispositivos compatíveis, como equipes de referência e elaboração e implementação de projeto terapêutico individualizado.

As pessoas com TMG que moram de outras maneiras fornecem elementos importantes para o planejamento de futuros modos de apoio à moradia dessa clientela. Por meio deles, pudemos identificar tanto barreiras quanto oportunidades para a inserção social, oferecidas pelo cotidiano na cidade. Um suporte atento e flexível, extramuros, pode ser decisivo para a manutenção de suas moradias e uma inserção ao menos funcional no espaço urbano e, para alguns, para a superação da institucionalização em albergues públicos e privados a que estão sujeitos.

No limite, o que parece estar em jogo para ambas as clientelas acompanhadas e também 
para o aparato institucional que procura se ocupar do problema é a complexa articulação de estrutura, suporte e acompanhamento na medida certa para garantir, mais do que um abrigo/moradia, a constituição de um lar/habitação, sendo este último ao mesmo tempo condição e consequência da inserção social.

\section{Colaboradores}

JP Furtado, A Tugny, AP Baltazar, S Kapp, E Nakamura, CM Generoso, FCB Campos e AMC Guerra participaram da redação e revisão geral do texto. Além disso: A Tugny, S Kapp e AP Baltazar elaboraram e redigiram a análise da Arquitetura; CM Generoso e AMC Guerra elaboraram e redigiram análise da Psicanálise; JP Furtado e FCB Campos elaboraram e redigiram análise da Saúde Coletiva; E Nakamura elaborou e redigiu análise da Antropologia.

\section{Agradecimento}

Ao Cnpq, que financiou a presente pesquisa.

\section{Referências}

1. Furtado JP. Avaliação da situação atual dos Serviços Residenciais Terapêuticosexistentes no SUS. Cien Saude Colet 2006; 11(3):785-795.

2. Furtado JP, Pacheco RA. Moradias para pacientes psiquiátricos em Campinas: análise de uma experiência. J Bras Psiquiatria 1998; IV:44-57.

3. Brasil. Ministério da Saúde (MS). Secretaria Executiva. Legislação em saúde mental: 1990-2002. Brasília: MS; 2002.

4. Brasil. Ministério da Saúde (MS). Coordenação Geral de Saúde Mental, Álcool e Outras Drogas. Boletim Saúde Mental em Dados 2012; VII(10).

5. Thomson H, Thomas S, Sellstrom E, Petticrew M. The Health Impacts of Housing Improvement: A Systematic Review of Intervention Studies From 1887 to 2007. Am J Public Health 2009; 99(Supl. 3):S681S692.

6. Beaulieu A, Dorvil H, organizadores. L'habitation comme détermiant social de la santé mentale. Montreal: Acfas; 2004.

7. Morin P, Dorvil H. Dossier: Le logement social et l'hebergement. Nouvelles Pratiques Sociales 2001; 14(2):88-105.

8. Dorvil H. L'habitation et la santé mentale. In: Dorvil $\mathrm{H}$, Beaulieu $\mathrm{A}$, organizadores. L'habitation comme déterminant social de la santé mentale. Laval: Acfas; 2004.

9. Saraceno BA. Reabilitação como cidadania. In: Saraceno $\mathrm{BA}$, organizador. Libertando identidades: da reabilitação psicossocial à cidadania possível. Rio de Janeiro: TeCorá; 1999.

10. Tsemberis S, Rogers ES, Rodis E, Dushuttle P, Skryha V. Housing satisfaction for persons with psychiatric disabilities. J Community Psychol 2003; 31(6):581-590.

11. Nelson G, Sylvestre J, Aubry T, George L, Trainor J. Housing Choice and control, Housing Quality, and Control over Professional Support as Contributors to the Subjective Quality of Life and Community Adaptation of People with Severe Mental Illness. Adm Policy Ment Health \& Ment Health Serv Res 2007; 34(2):89-100.

12. Piat M, Ricard N, Lesage A. Evaluating life in foster homes for persons with serious mental illness: Resident and caregiver perspectives. $J$ Ment Health 2006; 15(2):227-242. 
13. Tsemberis S. L'intégration sociale des patients psychiatriques désinstitutionnalisés: l'expérience de New York. In: Beaulieu A, Dorvil H, organizadores. L'habitation comme déterminant social de la santé mentale. Montreal: Acfas; 2004.

14. Trieman N, Leff J, Glover G. Outcome of long stay psychiatric patients resettledin the community: prospective cohort study. Brit Med J 1999; 319(7201):1316.

15. Santos Junior HPO, Silveira MFA. Pratica de cuidados produzidos nos serviçosterapeuticos: percorrendo os trilhos de retorno a sociedade. Rev Esc Enferm Usp 2009; 43(4):788-795.

16. Vidal CEL, Bandeira M, Gontijo ED. Reforma psiquiátrica e serviços residenciais terapêuticos. J Bras Psiquiatr 2008; 57(1):70-79.

17. Cadernos IPUB. Desinstitucionalização. A experiência dos Serviços Residenciais Terapêuticos. Cadernos IPUB 2006; 12(22).

18. Wachs F, Jardim C, Paulon SM, Resende V. Processos de subjetivação e território de vida. Physis Rev Saúde Coletiva 2010; 20(3):895-912.

19. Sztajnberg TK, Cavalcanti MT. A arte de morar... na lua. Rev. Latinoam Psicopat Fund 2010; 13(3):457468.

20. Borysow IC, Furtado JP. Assistência social e saúde: o acesso de pessoas em situação de rua aos serviços de saúde mental. Cien Saude Colet 2012; 23(1):33-50.

21. Furtado JP, Nakamura E, Generoso C, Guerra A, Braga Campos F, Tugny A. Inserção social e habitação: um caminho para a avaliação da situação de moradia de portadores de transtorno mental grave no Brasil. Interface (Botucatu) 2010; 14(33):389-400.

22. Furtado JP. A avaliação de programas e serviços In: Campos GWS, Minayo MCS, Akerman M, Drumond Júnior M, Carvalho YM, organizadores. Tratado de Saúde Coletiva. São Paulo: Hucitec; 2006. p. 715-740.

23. Braga-Campos FC. O Modelo da Reforma Psiquiátrica e as modelagens de São Paulo, Campinas e Santos [tese]. Campinas: Unicamp; 2000.

24. Furtado JP. Equipes de referência: arranjo institucional para potencializar a colaboração entre disciplinas e profissões. Interface (Botucatu) 2007; 11(22):239-255.
25. Guerra AMC. Reabilitação psicossocial no campo da reforma psiquiátrica: uma reflexão sobre o controverso conceito e seus possíveis paradigmas. Rev. Latinoam. Psicopat Fund 1996; 2(2):83-96.

26. Campos GWS, Onocko Campos RT. Co-construção de autonomia: o sujeito em questão. In: Campos GWS, Minayo MCS, Akerman M, Drumond Júnior M, Carvalho YM, organizadores. Tratado de Saúde Coletiva. São Paulo: Hucitec; 2006.

27. Martin D. Noção de significado nas pesquisas qualitativas em saúde: a contribuiçãoda antropologia. Rev Saude Publica 2006; 40(1):178-180.

28. Mauss M. Sobre uma categoria do espírito humano - A noção de pessoa e a noção de eu. In: Mauss M. Sociologia e Antropologia. São Paulo: Cosac Naify; 2007.

29. Lévi-Strauss C. O pensamento selvagem. 3a Edição. Campinas: Papirus; 2002.

30. Nakamura E. Depressão na infância: uma abordagem antropológica [tese]. São Paulo: Universidade de São Paulo; 2004.

31. Duarte LFD. Indivíduo e pessoa na experiência da saúde e da doença. Cien Saude Colet 2003; 8(1):173183.

32. Gorz A. Metamorfoses do trabalho: busca do sentido, crítica da razão econômica. São Paulo: Annablume; 2003.

33. Lacan J. Função e campo da fala e da linguagem em psicanálise. In: Lacan J. Escritos. Rio de Janeiro: Jorge Zahar; 1998. p. 238-324.

34. Lacan J. Além da angústia de castração. In: Lacan J. A Angústia: Seminário livro 10 (1962- 1963). Rio de Janeiro: Jorge Zahar; 2005. p. 53-65.

35. Wajcman G. Intime exposé, intime extorque. [página na Internet]. [acessado 2010 set 28]. Disponível em: www.lacan.com/sympton8_articles/wajcman8. html

36. Fourez G. A construção das ciências: introdução à filosofia e à ética das ciências. São Paulo: Editora da Unesp; 1995.

Artigo apresentado em 29/08/2012

Aprovado em 26/09/2012

Versão final apresentada em 03/10/2012 
